
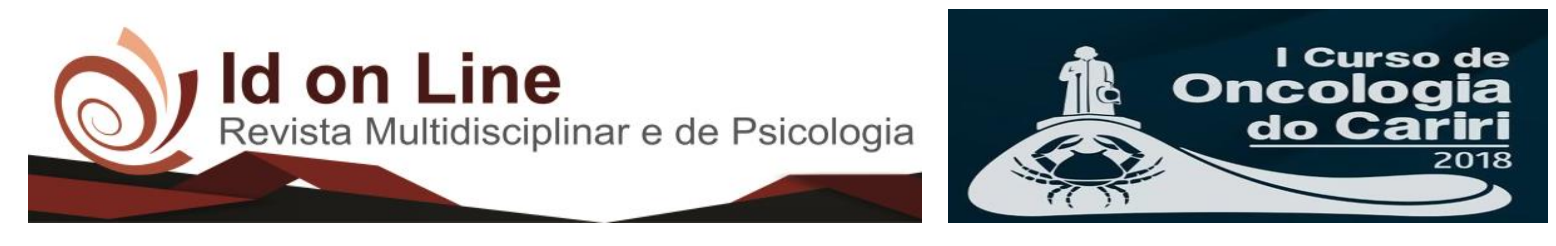

Resumo

\title{
BIOMARCADORES SALIVARES NO DIAGNÓSTICO DE CÂNCER ORAL
}

\author{
Francisca Seyla de Alencar Correia ${ }^{1}$, Iasmim Maria Luna Filgueiras ${ }^{1}$, Francisco Jadson Lima ${ }^{2}$
}

Introdução: Os biomarcadores são compostos imunoativos encontrados no corpo, comumente no sangue, urina, fluídos e tecidos corporais, que podem indicar função normal e homeostase ou identificam riscos de ocorrência de uma doença. Os marcadores tumorais são usados em oncologia para detectar alterações moleculares que sugiram presença de um câncer ou mesmo para acompanhar e tratar. A utilização de biomarcadores tem permitido a individualização de alguns tratamentos e o desenvolvimento da medicina personalizada e humanizada. O fluído salivar passou a ser utilizado como meio de diagnóstico para doenças sistêmicas e crônicas como o caso de neoplasias, tendo como exemplo o câncer de cavidade oral. Objetivo: Relatar o uso de biomarcadores salivares no diagnóstico de cânceres de cabeça e pescoço, tendo enfoque o câncer de cavidade oral. Métodos: Realizou-se uma revisão sistemática a partir das bases de dados disponíveis na Bireme com itens publicados no período de 2007 a 2015, em língua portuguesa. Foram encontrados 18 artigos dos quais apenas 3 foram escolhidos por seguirem critérios definidos acima. Resultados: Estudos realizados constaram duas correntes importantes de investigação nesta área, a proteômica e a genômica que estudam respectivamente, a utilização das proteínas e componentes genéticos salivares como biomarcadores de interesse clínico. A análise da saliva tem como finalidade identificar e seguir o progresso do paciente afetado, avaliando a eficiência do tratamento empregado. Na prática clínica a utilização de biomarcadores salivares como meio de diagnóstico precoce rastreia uma lesão neoplásica em seus estágios iniciais e permite ao profissional designar um quadro clinico correto e assertivo precocemente, tendo em vista ofertar ao paciente uma terapêutica mais adequada e com maior probabilidade de sucesso. Estudos avaliaram os genes CD44, EGFR, CICLINA DL, FAS/FASL, proteína p27, VEGF e metaloproteínases contribuem no diagnóstico de tumores de cabeça e pescoço, inclusive em seus estágios iniciais, tendo destaque o CD44 que colabora no diagnóstico e prognóstico de câncer oral. Conclusão: Evidências apontam que os usos de biomarcadores encontrados na saliva auxiliam diagnóstico precoce de doenças neoplásicas de cabeça e pescoço. A medida que as tecnologias necessárias para detecção de biomarcadores avançam, a importância da saliva como fluido diagnóstico torna-se mais aceito, oferecendo uma melhoria da saúde sistêmica e bucal.

Palavras Chave: Biomarcadores, Saliva, Câncer.

\footnotetext{
${ }^{1}$ Acadêmica de Odontologia do Centro Universitário Doutor Leão Sampaio

2 Doutor em patologia oral, odontólogo e professor do Centro Universitário Doutor Leão Sampaio;

Autor correspondente: seylalencar@gmail.com.
}

20 Id on Line Rev. Mult. Psic. V.12, N. 40. 2018 - ISSN 1981-1179 EDIÇÃO ESPECIAL: I CURSO DE ONCOLOGIA DO CARIRI / II JORNADA DE PESQUISA QUANTI-QUALITATIVA EM ONCOLOGIA. JUAZEIRO DO NORTE, 05 A 10 DE MARÇO DE 2018. Edição eletrônica em http://idonline.emnuvens.com.br/id 